\title{
Behavioural and Cognitive Treatment Interventions in Depression: An analysis of the Evidence Base
}

\author{
Joanna L. Iddon ${ }^{1}$, Lee Grant ${ }^{2}$ \\ ${ }^{1}$ Wilbraham Place Practice, London, UK \\ ${ }^{2}$ Efficacy CBT, London, UK \\ Email: jo@joiddon.com
}

Received January $30^{\text {th }}, 2013$; revised March $5^{\text {th }}, 2013$; accepted March $16^{\text {th }}, 2013$

\begin{abstract}
Copyright (C) 2013 Joanna L. Iddon, Lee Grant. This is an open access article distributed under the Creative Commons Attribution License, which permits unrestricted use, distribution, and reproduction in any medium, provided the original work is properly cited.
\end{abstract}

\begin{abstract}
Depression has been determined to be the leading cause of disability and the 4th leading contributor to the global burden of disease and is characterized by relapse, recurrence and chronicity (WHO, 2007). A systematic review of several meta-analyses on treatment outcome supports the view that Cognitive Behavioural Therapy (CBT) is an effective treatment (Butler et al., 2006). However, CBT is not a single intervention, but has evolved from various theoretical perspectives, resulting in different theoretically congruent treatment techniques for depression. It is therefore important to understand which treatment approaches may be the most effective. This review provides an analysis of the evidence base comparing CBT with Behavioural Activation (Martell et al., 2010). 3rd wave approaches and the Six Cycles Maintenance \& Treatment Model (Moorey, 2010) are presented in the context of how they can add to the effective treatment of depression.
\end{abstract}

Keywords: Depression; Cognitive Behaviour Therapy; Behavioural Activation; Metacognitive Therapy; Mindfulness

\section{Introduction}

Depression has been determined to be the leading cause of disability and the 4th leading contributor to the global burden of disease and is characterised by relapse, recurrence and chronicity (WHO, 2006). A systematic review of several metaanalyses on treatment outcome supports the view that Cognitive Behavioural Therapy (CBT) is an effective treatment (Butler et al., 2006). However CBT is not a single intervention, but has evolved from various theoretical perspectives, resulting in different theoretically congruent treatment techniques for depression. It is therefore important to understand which treatment approaches may be the most effective.

\section{Cognitive Therapy}

Aaron Beck's cognitive model of depression (Beck, 1967, 1976) has been highly influential in informing treatment (Beck et al., 1979; Fennell, 1989). The central basis of Beck's theory is around the development of (dysfunctional) schemas (i.e. assumptions and attitudes) developed from previous experience, which lay dormant until activated, thus he advocates an "internal" causation. The stress diathesis model suggests that certain beliefs constitute a vulnerability to depression depending on our life experiences, stressors may interact with specific cognitive vulnerabilities to trigger depression (Clark, 1989). Anxiety states. In Hawton (1989) etc. as cited in the Fennel reference above.

Although the pure practice and effective implementation of CBT that Beck advocated is complex, the principles for treat- ment are relatively simple: "the therapist helps a patient to unravel his distortions in thinking and to learn alternative, more realistic ways to formulate his experiences". Patients tend to have a misconception of events and need to reappraise and learn more adaptive attitudes (Beck, 1976). Beck described the underlying rationale of a "negative cognitive triad" (self-current experience-future). Beck's cognitive therapy for depression was designed to be short term and structured (Beck et al., 1979; Leahy, 2006) and consists of Activity Scheduling (AS) in the early stages of the treatment of depression, particularly in those patients with significantly diminished levels of activity and cognitive techniques (to identify, question and modify maladaptive thought processes, life rules and core beliefs).

There are multiple studies showing evidence that Beckian CBT is effective, including being more effective (e.g. Butler et al., 2006; Fennel, 2002; Rush et al., 1977) or at least as effective (Blackburn et al., 1981; Murphy et al., 1984) as antidepressant medication, although this may depend on therapist experience Hollon et al., 1992). Beckian CBT has also been evidenced to be useful in terms of preventing relapse (Murphy et al., 1984; DeRubeis, 2005; Kovacs et al., 1981; Blackburn et al, 1986). There have been a number of meta-analyses (Paykel et al., 2005; Dobson, 1989; Gloaguen et al., 1998) which showed that CT was no less effective than medication and quite possibly had longer lasting effects. Studies have hypothesised that this is related to concrete "symptom focussed" methods of cognitive therapy (DeRubeis \& Feeley, 1990), through teaching compensatory skills (Barber \& DeRubeis, 1989) and through in-session cognitive changes (Tang \& DeRubeis, 1999; 2005). 
Beck's daughter, Judith has gone on to develop an up-to-date "brand" of cognitive Therapy (Beck, 1995).

\section{Behavioural Therapy}

Behavioural treatment of depression can be traced back at least to Ferster (1973), based on Skinner's principles (Skinner $\&$ Burrhus, 1957) who recommended a functional or "behavioural" analysis, which can be used to "discover the kinds of circumstances that can increase or decrease the frequency of different ways of acting". Lewinsohn (1974) took a slightly different behavioural approach, focusing on increasing rewarding behaviour. Behavioural techniques are of course incorporated into CT (Beck et al., 1979), but are differentiated from Beckian cognitive approaches of AS focusing on thinking distortions preventing unhelpful behaviours and maintaining and developing helpful behaviours; “... the techniques are presented within the framework of a cognitive rationale, e.g., they are explicitly used to test thoughts which block engagement in such activities, or lead people to discount or devalue what they do, and thus help to maintain the depression" (Fennel, 1989).

\section{But What Is the Active Ingredient? A Component Analysis}

In 1996, Jacobson and colleagues published a landmark paper of a component analysis of cognitive-behavioural treatment for depression. The study compared three different conditions, 1) Becks behavioural activity monitoring (BA); 2) behavioural activity with a teaching component designed to schedule activities to modify automatic thoughts (AS); and 3) full Beckian Cognitive Therapy (CT). All conditions were administered by skilled therapists and sessions were monitored for quality control and adherence to protocol. Its results and conclusions showed that all three treatments were equally effective both immediately and at 6-month follow-up, but were radical in the sense that BA and AS were equally as effective as CT at modifying negative thoughts and maladaptive attributional styles, even though in BA these were not specifically targeted. To be clear, this component analysis study suggested that the active ingredient in Beck's cognitive therapy was the behavioural activation component, which is distinct from Beck et al. (1979) which states that interventions aimed at cognitive structures or core schemas are the active change mechanisms.

Martell and colleagues (Martell et al., 2001) went on to develop "Behavioural Activation" as an individual form of therapy, which is an expanded version of the Beck behavioural approach of activity scheduling. Veale (2008) describes that BA has two main focuses:

1) The use of avoided activities as a guide for activity scheduling;

2) Functional analysis of cognitive processes that involve avoidance.

Martell et al. (2001) provides a detailed book on the process, which provides a clear rationale and detailed discussion of treatment aims and directions and is associated with a model to guide formulation and treatment. In BA, "the focus is on the context of people's lives rather than their thoughts, neurotransmitters, beliefs or the psychological conflict thought to be inside them", thus it advocates an "external" contextual focus. Martell and colleagues (2001) provide a compelling argument for why internal causes may not be the "zeitgeist" after all. They explore the assumption that people tend to think of depression as some sort of "medical illness" and this is supported by the ICD-10 diagnostic criteria of depression (WHO, 1992). Martell's concept is that depression is rather a process occurring in the context of difficult events in people's lives, for example a person may feel depressed because their wife leaves them (i.e. the environment acts upon the person) which leads to a "depressed response" (the person has an impact on the environment). The basis for their form of BA is that a person's response with depressive behaviour usually makes sense and Martell points out that given a particular history, and current context, withdrawal, avoidance, inactivity and rumination can be understood as "adaptive coping strategies", and this is the basis of their theory.

The primary focus in BA is targeting avoidance and "activating clients" but is not simply about getting individuals to do more. It's about the quality and precise nature of their behaviours and the focus is on function (not form). So, for example, one may work with a client on refining an over-compensatory behaviour, e.g. in the example of a man being left by his wife, he may "overcompensate" by buying elaborate presents for his children, or taking them on trips after a long day at school, whereas he found much more value in developing simpler activities such as kicking a ball on the common, taking them for fish \& chips, planting tomatoes and reading a story to them in bed.

\section{Thoughts in Behavioural Activation}

In terms of thoughts and beliefs, the BA perspective is different from the cognitive perspective. In BA the process of thinking, but not the content of thinking is an important focus of treatment (e.g. "What is useful about that thought?" "What are the consequences of having that particular thought?" and may draw on "mindful" techniques to consider the minute details of an activity. Again beliefs are treated differently, and BA is not concerned about uncovering the real beliefs of a client (or 'catching' their thoughts), the focus is on getting (re-)involved in their lives so that their behaviours will be positively reinforced. Beck et al. (1979), by contrast advocates that negative automatic thoughts (NATS) are a product of errors in processing and therapy helps a client practice identifying NATS (within a context) and challenging these "What is the evidence?" "What alternative views are there?" In this context behavioural change is seen as a necessity to test and challenge negative automatic thoughts, assumptions and schemata.

\section{Comparison of BA and CT}

In 2006, Dimidjian and his team published the outcome data for a robust RCT, showing that BA was comparable to medication and both BA and medication significantly outperformed cognitive therapy. Other studies have shown that BA is at least as comparable (Butler et al., 2006; Ekers et al., 2008) but there may be advantages of BA over CT as a more "streamlined" form of therapy. Spates and colleagues (2006) published a systematic review of the literature in $\mathrm{BA}$ and a meta-analysis showed an extremely favourable outcome, in terms of both individual and group treatments, although there was no comparison with CT. The authors pointed out that at that stage there were still only 11 papers to review, which when guiding the 
worldwide treatment of depression and influencing government guidelines is relatively few. Cuijpers et al. (2007) meta analysis conducted a wider search on BA and was able to compare this to cognitive treatments finding a greater effect size for BA over AS and CT. The review has limitations but still has an encouraging support for the behavioural approaches. Sturmey (2009), published a useful systematic review which suggests that BA may have a lower drop-out rate than CT and CBT, with lower relapse rates than Paroxetine as well as being cheaper, without the risk of side effects. He also states the evidence is that BA may be more useful in certain groups with whom CT and CBT is less effective such as those with severe or long-term depression, substance abusers and people with dementia.

\section{So What to Use?}

In the UK the NICE guidelines for managing depression in primary care published in 2007 and 2009 indicated "CBT" (non-specific) as one of the recommended interventions, alongside an SSRI antidepressant if appropriate. If there is co-morbid depression with anxiety, the guidelines recommended targeting the depression first as this can also help alleviate the symptoms of anxiety. In the USA in 2010 the American Psychiatric Association published similar guidelines, advocating CBT as do the Canadian guidelines (CANMAT-Parikh et al., 2009) - in the Canadian review paper, further research is encouraged before a clear distinction can be made between the efficacy of CT and BA.

Roth \& Pilling (2008) have included both CT and BA (Beck et al., 1979; Martell et al., 2001) as evidence based methodologies in depression in their guidance on competencies. When looking at the cognitive and behavioural techniques advocated in their specific CBT competencies framework (www.ucl.ac. $\mathrm{uk} / \mathrm{CORE} /$ ) it is interesting that they detail activity monitoring and scheduling, guided discovery and questioning, thought records and eliciting key cognitions, but in general terms without making reference to choosing between a specific technique, thus as they say "the jury is still out". One could argue that one is "covering the bases" by using traditional CT as it does have an established and respected evidence base. However, BA does appear to be a powerful (and relatively straightforward) technique that should be emphasised in any treatment of depression, especially during the early stages and in cases that are at least moderately severe. So BA, with possible effectiveness over CT, certainly seems to possibly be the treatment of choice for the future.

\section{The 3rd Wave Approaches}

Or is it? The evidence base suggests that at present, BA is at least equal to $\mathrm{CT}$ when treating depression and may be superior. However, it is important to mention two further recent cognitive approaches of changing patients' relationships to their thoughts, which whilst having limited evidence bases at this time, seem to hold promise: Meta-Cognitive Therapy (Wells, 2009; Fisher \& Wells, 2009) and Mindfulness approaches (Williams et al., 2007).

Metacognitive therapy (Wells, 2009; Fisher \& Wells, 2009) puts another "spin" on the consideration of thoughts. Once again it is distinct from Beck's schema theory (Beck, 1967; 1976) and instead proposes that an "executive control processor" influences firstly metacognitive process (i.e. referring to the level of thinking process that involves the generation over the content of thoughts) responsible for healthy and unhealthy regulation of the mind. Secondly the process of selective attention attends the person to ambiguous triggers and thus increases the vulnerability of activation to NATs. An example of a metacognitive process might be:

Content Thought "I am completely useless as a husband and parent and will never be any good to anyone".

Underlying Metatcognitive beliefs: "If I can understand $\{a-$ $k$ a ruminate\} what I did wrong then I can fix it" leading to worry or rumination; or "I am responsible and should be punished" leading to self attaching thoughts.

Wells (2009) proposes that emotional disorders such as depression are caused by the "metacognitions that give rise to thinking styles that lock the individual into prolonged and recurrent states of negative processing". Treatment for depression focuses on understanding the causes of rumination and then removing this unhelpful process. A model and treatment plan is proposed, including specific interviews which guide the therapist to developing a formulation diagram (Wells, 2009). The focus of treatment is on first recognising and then changing the metacognitive beliefs (e.g. from "I cannot control my negative thoughts" to "I can postpone worrying"; or from "I need certainty" to "I can accept uncertainty") and not to focus on the content of the rumination.

Mindfulness based cognitive therapy (Williams et al., 2007) is also emerging as a treatment with a significant following currently considered to be most useful in treating patients with recurrent depression, whilst they are in remission. However, mindfulness potentially has a wider application and there are integral components to other evidence based CBT interventions (Linehan, 1993). This approach has been developed from meditative practices encouraging patients to adopt an observational stance to the continuous flow of automatic thoughts, emotions and the corresponding physical reactions. The basic premise is that it is how we attend to internal process and react to what is in our mind that is important. In essence by disengaging from negative patterns of mental activity in a "mindful" way (i.e. focussing in the "present") promotes wellbeing. Rebecca Crane (2009) has provided a useful summary book outlining the basic principles and treatment approach based on Williams and colleagues (2007).

\section{Summary, Conclusion and Future Directions}

As Roth \& Pilling (2008) point out:

" $C B T$ - gives the appearance of a unitary therapy, but $C B T$ is better seen as an increasingly diverse set of problem-specific interventions. What is more, these draw on a common base of cognitive and behavioural models, the techniques overlap, but show significant variations in application".

This statement summarises the complex nature of the field of formulation and treatment in depression as it is today. The current evidence base suggests BA be the current treatment of choice, (which is distinct from AS in the cognitive paradigm) but the landscape may look very different in even a few years and so it is important to keep an open mind. Indeed further evidence is warranted before "doing away" with Beckian CBT, which has proved so successful in the clinical setting. Roth \& Pilling in 2008 point out that their research and recommendations will be out of date very quickly and will need constantly reviewing and updating to take into account new evidence of 
effectiveness of different treatment approaches prioritising behavioural change or cognitive change. Emerging new approaches appear to overlap, particularly in terms of working with the process of thoughts, and these may prove complementary to each other. It would be naive to think that "one size fits all", but arguable that you cannot have process change without content change and you cannot have content change without process change. As clinicians we are left with the dilemma of which intervention to match with particular presentations. Presently the literature does not clarify how the variance in effect size for a particular intervention is influenced by particular presentations.

It is important to state that depression, can present for many different reasons and each client needs to be treated individually and appropriately. For example the authors have found a non-genital sensate focus approach (Masters \& Johnson, 1970) useful for a couple who had ceased to have sexual intercourse, that led to one partner developing symptoms of depression. Another client depressed about being obese with cognitive and behavioural distortions around approaches to food and eating was successfully treated using Fairburn's (2003) transdiagnostic approach to eating disorders. Thus when choosing an appropriate treatment approach, both context and the collaborative conceptualisation of the presenting problem needs to be taken into account.

\section{Looking to the Future}

So ... for future consideration

1) What exactly are the differences between the CBT approaches (BA, AS, CT, MCT and Mindfulness) to treating depression in practice (rather than theory) and how do these complement each other?

2) What is the best approach to use with different clients? i.e. when do we know what is the best approach to use with whom?

3) Given that the approaches draw on a common base of cognitive and behavioural models, would a "trans-therapeutic" approach or single conceptualisation be appropriate, whereby overlapping evidence based approaches were incorporated into a unified application?

Based on this principle, Stirling Moorey (2010) has developed an empirically based six cycles maintenance model for depression in the form of a "vicious flower". This was developed based on clinical utility and current knowledge of the processes and maintenance factors in depression, with the aim to inform formulation, socialisation and treatment planning. It is a simple and clear model which will also be useful in teaching CBT, incorporating 2 cognitive cycles (automatic negative thinking and rumination/self attacking), 2 behavioural cycles (withdrawal/avoidance and unhelpful behaviour), a mood/emotion cycle and a motivation/physical symptoms cycle. Furthermore the model is innovative in having a potentially useful role in relapse prevention work.

\section{Acknowledgements}

With thanks to Stirling Moorey for allowing us early access to his manuscript.

\section{REFERENCES}

Barber, J. P., \& DeRubeis, R. J. (1989). On second thought: Where is the action in the cognitive therapy for depression. Cognitive Therapy and Research, 13, 441-457. doi:10.1007/BF01173905

Beck, A. T. (1976). Cognitive therapy and the emotional disorders. London: Penguin.

Beck, A. T. (1967). Depression: Clinical, experimental and theoretical aspects. New York: Harper and Row.

Beck, A. T., Rush, A. J., Shaw, B. F., \& Emery, G. (1979). Cognitive therapy of depression. New York: Guilford Press.

Beck, J. S. (1995). Cognitive Therapy: basics and beyond. New York: The Guilford Press.

Blackburn, I. M., Bishop, S., Glen, I. A. M., Whalley, I. J., \& Christie, J. E. (1981). The efficacy of cognitive therapy in depression: A treatment trial using cognitive therapy, pharmacotherapy, each alone and in combination. British Journal of Psychiatry, 139, 181-189. doi:10.1192/bjp.139.3.181

Blackburn, I. M., Eunson, K. M., \& Bishop, S. (1986). A two year naturalistic follow-up of depressed patients treated with cognitive therapy, pharmacotherapy and a combination of both. Journal of Affective disorders, 10, 67-75. doi:10.1016/0165-0327(86)90050-9

Butler, A. C., Chapman, J. E., Forman, E. M., \& Beck, A. T. (2006). The empirical status of cognitive behaviour therapy: A review of meta-analyses. Clinical Psychology Review, 26, 17-31. doi:10.1016/j.cpr.2005.07.003

Crane, R. (2009). Mindfullness based cognitive therapy. London: Routledge Press.

Cuijpers, P., van Straten, A., \& Warmerdam, L. (2007). Behavioural activation treatments of depression: A meta analysis. Clinical Psychology Review, 27, 318-326. doi:10.1016/j.cpr.2006.11.001

DeRubeis, R. J. (2005). Cognitive therapy vs medications in the treatment of moderate to severe depression. Archives of General Psychiatry, 62, 409-416. doi:10.1001/archpsyc.62.4.409

DeRubeis, R. J., \& Feeley, M. (1990). Determinants of change in cognitive therapy for depression. Cognitive Therapy and Research, 14 469-482. doi:10.1007/BF01172968

DeRubeis, R. J., Gelfand, L. A., Tang, T. Z., \& Simons, A. D. (1999). Medications vs cognitive behaviour therapy for severely depressed outpatients: A mega-analysis of four randomised comparisons. American Journal of Psychiatry, 156, 1007-1013.

Dimidjian, S., \& Team of 12 (2006). Randomized trial of behavioural activation, cognitive therapy, and antidepressant medication in the acute treatment of adults with major depression. Journal of Consulting and Clinical Psychology, 74, 658-670. doi:10.1037/0022-006X.74.4.658

Dobson, K. (1989). A meta analysis of the efficacy of cognitive therapy for depression. Journal of Consulting and Clinical Psychology, 57, 414-419. doi:10.1037/0022-006X.57.3.414

Ekers, D., Richards, D., \& Gilbody, S. (2008). A Meta-analysis of randomised trials of behavioural treatment in depression. Psychological Medicine, 38, 611-623. doi:10.1017/S0033291707001614

Fairburn, C. (2003). Cognitive behaviour therapy and eating disorders. New York: The Guilford Press.

Fennel, M. (2002). Depression. In K. Hawton, P. M. Salkovskis, J. Kirk, \& D. M. Clark (Eds.), Cognitive behaviour therapy for psychiatric problems (pp. 169-253).

Ferster, C. B. (1973). A functional analysis of depression. American Psychologist, 28, 857-870.

Fisher, P., \& Wells, A. (2009). Metacognitive therapy. London: Routledge Press.

Gloaguen, V., Cottraux, J., Cucharet, M., \& Blackburn, I. (1998). A meta-analysis of the effects of cognitive therapy in depressed patients. Journal of Affective Disorders, 49, 59-72. doi:10.1016/S0165-0327(97)00199-7

Hawton et al. (1989). D Clark Chapter in cognitive behaviour therapy for psychiatric problems. Oxford: Oxford University Press.

Hollon, S. D., DeRubeis, R. J., Evans, M. D., Wiemer, M. J., Garvey, M. J., \& Grove, W. M. (1992). Cognitive therapy, pharmacotherapy and combined cognitive-pharmacotherapy in the treatment of depression. Archives of General Psychiatry, 49, 774-781. doi:10.1001/archpsyc. 1992.01820100018004

World Health Organisation (1992). International classification of dis- 


\section{J. L. IDDON, L. GRANT}

eases. Geneva: World Health Organisation.

Jacobson, N. S., Dobson, K. S., Truax, P., Addis, M. E., Koerner, K., Gollan, J. K., Gortner, E., \& Prince, S. E. (1996). A component analysis of cognitive-behavioural treatment for depression. Jounral of Consulting and Clinical Psychology, 64, 295-304. doi:10.1037/0022-006X.64.2.295

Kovacs, M., Rush, A. T., Beck, A. T., \& Hollon, S. D. (1981). Depressed outpatients treated with cognitive therapy or pharmacotherapy: A one year follow-up. Archives of General Psychiatry, 38, 3339doi:10.1001/archpsyc.1981.01780260035003

Leahy, R. L. (2006). Contemporary cognitive therapy. New York: The Guilford Press.

Lewinsohn, P. M. (1974). A behavioural approach to depression. In R. J. Freedman, \& M. Katz (Eds.), The psychology of depression (pp. 157-174). Oxford: Wiley.

Linehan, M. M. (1993). Cognitive-behavioral treatment of borderline personality disorder. New York: Guilford.

Martell, C. R., Addis, M. E, \& Jacobsen, N. S. (2001). Depression in context: strategies for guided action. New York: WW Norton.

Masters, W. H., \& Johnson, V. E. (1970). Human sexual inadequacy. London: Churchill.

Moorey, S. (2010). The six cycles maintenance model: Growing a "Vicious Flower" for depression. Behavioural \& Cognitive Psychotherapy, 38, 173-184. doi:10.1017/S1352465809990580

Murphy, G. E., Simons, A. D., Wetzel, R. D., \& Lustman, P. J. (1984). Cognitive therapy and pharmacotherapy, singly and together, in the treatment of depression. Archives of General Psychiatry, 30, 667674.

NICE (2007). Clinical guidelines for the management of depression.

NICE (2009). Depression in adults (update). Depression: The treatment and management of depression in adults. National clinical practice guideline.

Parikh, S. V., Segal, Z. V., Grigoriadis, S., Ravindran, A. V., Kennedy, S. H., Lam, R. W., \& Patten, S. B. (2009). Canadian network for mood and anxiety treatments (CANMAT) clinical guidelines for the management of major depressive disorder in adults II. Psychotherapy alone or in combination with antidepressant medication. Journal of Affective Disorders, 117, S15-S25.

Paykel, E. S., Scott, J., Cornwall, P. L., Crane, C., Pope, M., \& Johnson,
A. L. (2005). Duration of relapse prevention after cognitive therapy in residual depression: Follow-up of controlled trial. Psychological Medicine, 35, 59-68. doi:10.1017/S003329170400282X

American Psychiatric Association (2010). Practice guidelines for the management of patients with major depressive disorder (3rd ed.). Arlington: American Psychiatric Association.

Roth, A. D., \& Pilling, S. (2008). Using an evidence-based methodology to identify the competencies required to deliver effective cognitive and behavioural therapy for depression and anxiety disorders. Behavioural and Cognitive Psychotherapy, 36, 129-147. doi: 10.1017/S1352465808004141

Rush, A. J., Beck, A. T., Kovacs, M., \& Hollon, S. D. (1977). Comparative efficacy of cognitive therapy and pharmacotherapy in the treatment of depressed outpatients. Cognitive Therapy and Research, 1, 17-38. doi:10.1007/BF01173502

Skinner, B. F., \& Burrhus, F. (1957). Verbal behavior. Acton, MA: Copley Publishing Group.

Spates, R. C., Pagoto, S., \& Kalata, A. (2006). A qualitative and quantitative review of behavioural activation treatment of major depressive disorder. Behaviour Analyst Today, 7, 508-521.

Sturmey, P. (2009). Behavioural activation: Is an evidence-based treatment for depression. Behaviour Modification, 33, 818-829. doi: $10.1177 / 0145445509350094$

Tang, T. Z., \& DeRubeis, R. J. (1999). Sudden gains and critical sessions in cognitive-behavioural therapy for depression. Journal of Consulting and Clinical Psychology, 67, 894-904. doi:10.1037/0022-006X.67.6.894

Tang, T. Z., DeRubeis, R. J., Beberman, R., \& Pham, T. (2005). Cognitive changes, critical sessions, and sudden gains in cognitive-behavioural therapy for depression. Journal of Consulting and Clinical Psychology, 73, 168-172. doi:10.1037/0022-006X.73.1.168

Veale, D. (2008). Behavioural activation for depression. Advances in Psychiatric Treatment, 14, 29-36.

Wells, A. (2009). Metacognitive therapy for anxiety \& depression. New York: The Guilford Press.

Williams, M., Teasdale, J., Segal, Z., \& Kabat-Zinn, J. (2007). The mindful way through depression. New York: The Guilford Press.

World Health Organisation Statistics (2007) Mental illness, depression. Geneva: World Health Organisation. 